\title{
STRUCTURED PROJECT LEARNING MODEL TOWARD IMPROVED COMPETITIVENESS IN BIDDING FOR LARGE CONSTRUCTION FIRMS
}

\author{
Hamzah Abdul-Rahman ${ }^{1}$, Chen Wang ${ }^{2}$, Shamini Batu Malay ${ }^{3}$ \\ ${ }^{1,2,3}$ Faculty of Built Environment, University of Malaya, 50603 Kuala Lumpur, Malaysia \\ E-mail: ${ }^{2}$ derekisleon@gmail.com (corresponding author) \\ Received 25 Oct. 2010; accepted 15 Apr. 2011
}

\begin{abstract}
Changes and uncertainties are inevitable in the construction industry so that contractors have to find ways to improve themselves in all aspects in order to enhance their competitiveness in tendering as it determines their survival in the industry. It is believed that experiences and knowledge of past projects have the potential to improve the competitiveness of the bids submitted. This study aims to propose project learning in a structured manner as an effective approach for improvements in bidding. Through a questionnaire survey, the five most significant benefits from project learning for the betterment of bid submissions were identified, namely: "improved accuracy in pricing", "more realistic estimates", "better evaluation of risks involved in tendering for a project", "less rework and repetition of mistakes", and "faster resolution of similar problems". Further, the five most suitable project learning methods for improvement in bidding were recommended, which included "periodic learning meeting", "documentation learning", "on job training", "debriefing", and "informal face-to-face interaction". Accordingly, a structured learning model toward improved bidding is developed for large construction firms.
\end{abstract}

Keywords: project learning, knowledge management, competitiveness, bidding, construction.

\section{Introduction}

The construction sector faces ever changing conditions, and those who are not prepared to meet the demands of the industry may ultimately fail. The complexity and uncertainty nature of construction industry makes it an industry full of challenges and difficulties. An ability to respond to the changes in the fast growing industry is important for survival (Mohamed, Anumba 2006). Therefore, construction companies have to be more innovative with the willingness to experiment and to adopt new developments and technologies through learning. Contractors who wish to stand on the stones of success have to pay substantial attention to improving their competitiveness in the tendering stage in order to survive in the construction industry. Because of the interdependent nature of construction, construction companies have a higher failure rate than many other types of companies (Kim 2010; McIntyre 2007). A concept of tendering, which has been practiced for a very long period, is that the lowest bidder wins the tender (Amarjit, Shoura 1998). In a competitive tendering situation, contractors have to consider both the success of a tendering and a reasonable amount of profit out of the project. People in a project team are the ones who are directly involved in the problem solving and decision making processes. Usually, at the end of a project, these individuals would move to other projects or functions and take away their experiences and knowledge in tendering. The end of a project is thus, the end of collective learning (Schindler, Eppler 2003).
In addition, many contractors are still lacking in certain criteria required for successful bidding causing them to loose most of the tenders. A huge number of contractors are not making full use of the past project histories and experiences which can assist the contractors in making critical decisions regarding tendering (Schindler, Eppler 2003; Maqsood et al. 2006). According to Maqsood et al. (2006), what is normally missing is a consistent system that gathers and keeps records of the key project history data including contextual information that can be later used at times of problematic solutions or opportunities, innovations tested and evaluated and for analysis on the development of project bidding.

\section{Project learning as integrated approach}

The view that knowledge is a valuable asset to construction companies has become widely acknowledged and has gained substantial attention in the recent years (Rezgui et al. 2010). Definitions of knowledge range from the practical to the conceptual to the philosophical and from narrow to broad in scope (Kanapeckiene et al. 2010). Knowledge can be classified into personal, shared and public, practical and theoretical, foreground and background, internal and external, hard and soft (Tserng et al. 2010), structured and unstructured (HaldinHerrgard 2000), knowing how and knowing that (Pathirage et al. 2007), and procession perspective and structural perspective (Jashapara 2004). Construction companies are in the need to possess sustainable learning efforts as the success of a project is highly influenced by 
the right combination of knowledge and experiences from previous projects (Park et al. 2010). Thus, the basic tasks of project management have to be complemented with project knowledge management activities for an effective management of projects. Project learning is also often referred as lessons learned (Disterer 2002; Greiner et al. 2007), project histories (Maqsood et al. 2006), project memory (Djaiz, Matta 2006) and management of project knowledge and experiences (Disterer 2002; Djaiz, Matta 2006). Regardless of the terms used, many scholars have argued that knowledge and experiences obtained from past projects make a valuable asset to construction companies and are significantly important to the development and improvement of construction companies. Project learning is a set of actions used by project team members to generate and share knowledge within and across projects. According to Djaiz and Matta (2006), project learning or project memory can be described as the history of a project and the experience obtained during the realization of the project. The project memory usually consists of knowledge regarding the context as well as the problem solving rationale.

\subsection{Project learning as important element in construction}

Companies learn most within projects, but are unable to pass on their experiences as these knowledge and experiences which can be reused in the future projects are kept in the mind of the team members. Therefore, the management of knowledge and experiences from projects is considered as an essential function of knowledge management (Heo et al. 2010). In addition, cooperative project learning is fundamental to the processes of knowledge management which includes knowledge sharing, knowledge generation and knowledge integration. Fig. 1 illustrates the flow of knowledge in project learning.

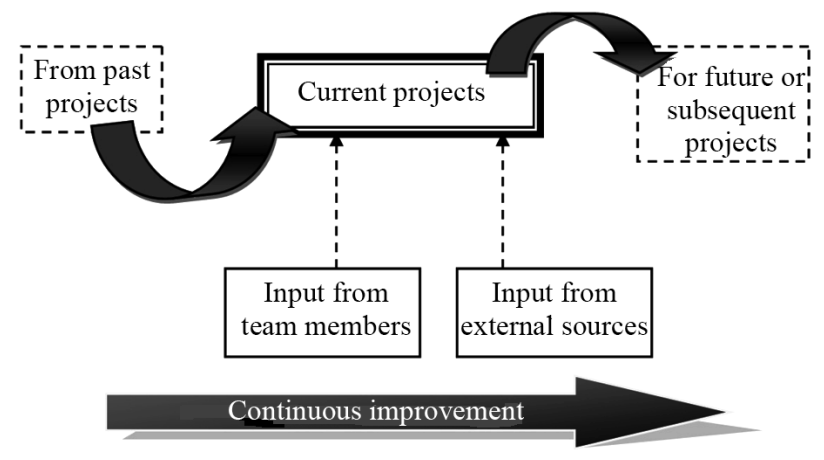

Fig. 1. Flow of knowledge in project learning

Besides that, knowledge sources of an organization can be internal or external to the organization where these resources are referred as external and internal knowledge banks. Maqsood et al. (2006) highlighted project histories and knowledge as a key element of the internal knowledge bank of a company. A wise and effective usage of these project histories would facilitate the integration process and improves the flow of knowledge. In relation to that, they argued that the implementation of knowledge mana- gement should provide project histories an importance of strategic concern. Apart from that, knowledge management is deemed to give project histories a high level of emphasis especially in the creation and management of project memories. This is strongly supported by the fact that project histories acts as mediums through which tacit knowledge is turned explicit, disseminated and shared throughout the organization (Maqsood et al. 2006). Thus, project learning has a crucial role to play in the process capturing and utilizing tacit knowledge of a project.

\subsection{Structured project learning to maximize utilization of project histories}

Learning within and across projects does not happen naturally as it is a complex process that needs to be managed (Williams 2008) in a structured and systematic manner. Furthermore, as mentioned before, construction projects in particular are complex entities and learning from a complex system requires a more sophisticated and innovative approach than simply writing down the lessons (Williams 2008). According to Maqsood et al. (2006), it is necessary for organizations to have a system through which project histories can be developed, evaluated and measured. They added on that the experiences and valuable knowledge assets from past projects need to be generated, validated and sustained in a manner that allows retrieval, transfer and future reanalysis.

In defining structured project learning, the word "structure" means "the way in which the parts of a system or object are arranged or organized, or a system arranged in this way" (Cambridge Advanced Learner's Dictionary 1992). The word "structured" on the other hand, can be defined as "organized in a clear way that lets you see the relationship between the parts" (Macmillan English Dictionary 2002). Based on the two definitions provided in the respective dictionaries, structured may mean to have a system arranged in a systematic and organized form. In the process of arriving at the meaning of structured project learning, project learning can be referred as a set of actions used by project team members to generate and share knowledge within and across projects. Thus, structured project learning refers to a set of systematically arranged actions used by project teams to create and share knowledge within and across projects. In other words, structured project learning involves activities of project learning that are arranged in a more organized and systematic manner to ensure effective learning.

\subsection{Needs for project learning to be implemented in a structured manner}

Learning from a project can take place at anytime, but the effectiveness and the quality of lesson learnt is still questionable. According to Maqsood et al. (2006), for an optimal and effective learning to occur, it is essential to have processes and structures to help people in creating new knowledge in order for them to continuously improve them. Along with that, organizations are in need to develop a framework to decide on the important information and knowledge to be captured from the current 
projects (Maqsood et al. 2006). In highlighting the importance of structured project learning, a survey conducted by Williams (2008) revealed that a huge number of project managers assigned the highest importance to formal procedures compared to other practices such as narratives, external facilitators and interviews. This provides evidence that better structured and standardized procedures of learning are the key factors in achieving successful learning from projects. At the same time, systematically collected project profiles and contact persons would facilitate the reuse of knowledge in other projects.

Apart from that, a systematic exchange of knowledge and experiences is necessary as it makes the acquainting of new employees relatively easier (Disterer 2002). Furthermore, learning in organizations rarely occurs due to lack of mechanisms to capture the knowledge in place (Maqsood et al. 2006). According to Williams (2008), more complex patterns in an organization are more likely to be discovered only by a systematic learning effort. In addition, Davenport et al. (1998) have identified standard and flexible knowledge structure as one of the factors that lead to successful knowledge management. Thus, a standard framework for learning enables an organization to utilize its resources in the most optimal manner.

\subsection{Project learning for improved bidding}

Tendering is a process that deals with critical and important decisions, making it a risky and significant part of the construction industry. Construction companies prefer to perform their project tasks including tendering based on their past experiences rather than following a text book approach or conventional analytical approaches (Wong et al. 2010). However, project expertise is highly personal and persistently tacit. This characteristic of project knowledge creates the necessity for project learning activities to facilitate the learning process within and across projects. Therefore, repositories that contain detail and important knowledge of previous projects would provide the construction companies a platform for reference when preparing bid submissions in the future. Three case studies on major contractors with turnover over one billion Australian dollars conducted by Maqsood et al. (2006) showed that the repositories that contain detailed knowledge and data from previous projects can be used by personnel involved in tendering for new projects. It emerged that the pre-tendering team places an increased value on the use of project histories in the pre-tendering stage. All these studies and research are clear evidence that project learning is capable of providing many added advantages to contractors in sustaining a high level of competitiveness especially through improved bid submissions. However, literatures of project learning have not fully explored the utilization of project knowledge and experiences for improved bidding. Even though Maqsood et al. (2006) have pointed out the potential of project histories in improving bid submissions, they only paid attention to the application of project learning in general management.

\section{Research methods and procedures}

Two types of research methods have been employed including a preliminary interview survey as a qualitative approach and a questionnaire survey as a quantitative approach. The preliminary interviews were conducted in the initial stage of the research. Preliminary interviews are usually conducted to obtain applicable information in relation to the research at the early stage of research which would help in ensuring the relevance of the research. In this study, preliminary interviews were conducted to identify the potential benefits in implementing project learning for improved bidding. A list of benefits was prepared prior to the preliminary interviews based on the literature review. Each preliminary interview was scheduled for a period within 10 to 15 minutes. The 17 interviewees were selected from various professionals including 3 developers, 5 consultants, and 9 contractors who are large and top firms in the construction industry to ensure the validity and reliability of the information obtained. The scope of the preliminary interview survey covers the entire Malaysia.

The questionnaire survey targeted only the class "A" contractors who have registered themselves with the "Pusat Khidmat Kontraktor" (PKK 2010). Contractors who belong to class "A" were chosen because these contractors represented the highest financial limits. Since the literature suggests that the implementation of project learning mostly takes place in bigger companies, a survey on the class "A" contractors would be more appropriate to demonstrate the effort of contractors in employing project learning. However, this also contributes as a limitation of this study. Table 1 shows the classification for contractors by "Pusat Khidmat Kontraktor" (PKK 2010). Overall 501 questionnaires were distributed to private based construction companies in Malaysia. There were 74 forms completed and returned. Table 2 and Table 3 show the brief profiles of these 74 respondents.

Table 1. Financial limits (construction cost) of contractors under "Pusat Khidmat Kontraktor" (PKK 2010)

\begin{tabular}{c|l}
\hline Class & \multicolumn{1}{|c}{ Financial Limits (RM) } \\
\hline A & Exceeding $10,000,000$ \\
\hline B & $5,000,001$ to $10,000,000$ \\
\hline C & $2,000,001$ to $5,000,000$ \\
\hline D & 500,001 to $2,000,000$ \\
\hline E & 200,001 to 500,000 \\
\hline
\end{tabular}

Table 2. Current position of respondents in their firms

\begin{tabular}{|c|c|c|c|c|c|c|}
\hline & \multicolumn{5}{|c|}{ Current Positions } & \\
\hline & 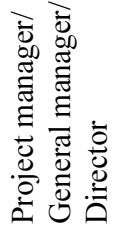 & 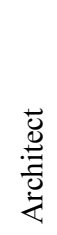 & $\begin{array}{l}\dot{\bar{d}} \\
\stackrel{\Xi}{00} \\
\dot{\square=}\end{array}$ & 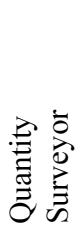 & 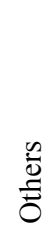 & 豞 \\
\hline Number & 37 & 1 & 3 & 20 & 13 & 74 \\
\hline Percentage & 50 & 1.4 & 4.0 & 27.0 & 50 & 100 \\
\hline
\end{tabular}


Table 3. Working experience of respondents

\begin{tabular}{|c|c|c|c|c|}
\hline \multicolumn{4}{|c|}{ Working Experience (Years) } & \\
\hline$<5$ & $5-10$ & $10-15$ & $>15$ & Total \\
\hline 15 & 22 & 13 & 24 & 74 \\
\hline 20.3 & 29.7 & 17.6 & 32.4 & 100 \\
\hline
\end{tabular}

\section{Research findings and discussions}

\subsection{Do contractors in Malaysia implement project learning in a structured manner?}

In determining whether contractors have adopted a systematic way of learning, several factors that used in the questionnaire survey were identified during the preliminary interview survey. These factors include "employment of individuals especially for project learning purposes", "regular meetings", "specific procedures or system for keeping record", "standardized methods of reviewing past project bid submissions", and "frequent and regular project learning activities". In the questionnaire survey, only $29.7 \%$ respondents have employed individuals handling project learning. Many companies did not employ individuals handling project learning because they stated that the current staff structure were sufficient to carry out their daily work. The questionnaire survey highlights that more than half $(66.2 \%)$ respondents have regular meetings in construction sites. The respondents suggested that meetings on regular basis are important for learning. It is worth noting that around half $(52.7 \%)$ respondents in the questionnaire survey have specific procedures or system for keeping record and standardized methods of reviewing past project bid submissions. These $52.7 \%$ respondents stated that construction companies in Malaysia did not have a proper system to keep record and especially in reviewing them. In addition, $25.7 \%$ respondents kept record of their bid submissions for the sake of accreditation, but fail to review the captured experiences and knowledge in a regular and systematic manner and to utilize them. The questionnaire results proposed that $56.8 \%$ respondents carried out project learning activities in a regular basis. Beside this, $28.4 \%$ respondents conducted project learning activities only when a certain problem became serious.

\subsection{Potential benefits of employing project learning for improved bidding}

The questionnaire survey identified eleven benefits of employing project learning for the betterment of bid submissions as shown in Table 4. The five most significant benefits include "improved accuracy in pricing", "more realistic estimates", "better evaluation of risks involved in tendering for a project", "less rework and repetition of mistakes", and "faster resolution of similar problems". The mean values for each kind of benefit are tabulated in Table 4. The values scaled from 1 to 5, which indicated the level of significance of benefits from low to high.

"Improved accuracy in pricing" was ranked by respondents as the top benefit with a mean value at 4.4054 . Respondents commented that the knowledge and experiences gained during the pricing process would equip the individuals with the skills to price the tenders in a more precise manner. "More realistic estimates" was ranked as the second top benefit with a mean value at 4.2703. Respondents commented that errors and miscalculations could easily take place in estimating so that the knowledge from past experiences could ensure the estimators being well versed with the proper ways in producing practical estimates because certain knowledge could only be obtained through experience. This in turn would produce more realistic estimates.

As shown in Table 4, "better evaluation of risks involved in tendering for a project" was ranked as the third most significant benefit with a mean value at 4.2703. Construction tendering involves various forms of risks regardless of the procurement methods adopted. The respondents suggested that project learning could contribute significantly towards a better evaluation of project risks and the risk evaluation was greatly dependent on the experiences from past projects. Respondents ranked "less rework and repetition of mistakes" as the fourth benefit and they commented that it was important to note that the tendency for errors and mistakes to occur during the bidding stage is relatively higher in the construction industry and these errors and mistakes related to cost. Therefore, it is essential to ensure that errors and mistakes are not

Table 4. The potential benefits of implementing past project learning for improvements in the future bid submissions

\begin{tabular}{|c|c|c|c|c|c|c|c|}
\hline No. & Benefits & $\mathrm{N}$ & Min. & Max. & Mean & Std. Dev. & Rank \\
\hline 1. & Improved accuracy in pricing & 74 & 2.00 & 5.00 & 4.4054 & .66041 & 1 \\
\hline 2. & Increased speed of estimating & 74 & 2.00 & 5.00 & 4.0135 & .73080 & 8 \\
\hline 3. & More realistic estimates & 74 & 3.00 & 5.00 & 4.2703 & .55634 & 2 \\
\hline 4. & Higher speed of pricing & 74 & 2.00 & 5.00 & 3.6757 & .89302 & 10 \\
\hline 5. & Increase in the competitiveness of the bid price submitted & 74 & 2.00 & 5.00 & 4.0811 & .78960 & 7 \\
\hline 6. & Wiser bid or no bid decision & 74 & 2.00 & 5.00 & 3.9054 & .76156 & 9 \\
\hline 7. & Better evaluation of risks involved in tendering for a project & 74 & 3.00 & 5.00 & 4.2703 & .62586 & 3 \\
\hline 8. & Reduced cost of tendering & 74 & 1.00 & 5.00 & 3.3649 & 1.06725 & 11 \\
\hline 9. & Faster resolution of similar problems & 74 & 1.00 & 5.00 & 4.1081 & .75066 & 5 \\
\hline 10. & $\begin{array}{l}\text { Increased efficiency of the individuals involved in bid } \\
\text { submissions }\end{array}$ & 74 & 3.00 & 5.00 & 4.0946 & .64466 & 6 \\
\hline 11. & Less rework and repetition of mistakes & 74 & 2.00 & 5.00 & 4.1622 & .77684 & 4 \\
\hline
\end{tabular}


Table 5. The suitable project learning methods for improvement in bidding

\begin{tabular}{|c|c|c|c|c|c|c|c|c|}
\hline \multirow[b]{2}{*}{ No. } & \multirow[b]{2}{*}{ Methods } & \multicolumn{3}{|c|}{ Recommended } & \multicolumn{3}{|c|}{ Not recommended } & \multirow[b]{2}{*}{ Rank } \\
\hline & & $\begin{array}{l}\text { Implemented } \\
\text { before }(\%)\end{array}$ & $\begin{array}{l}\text { Not imple- } \\
\text { mented } \\
\text { before }(\%)\end{array}$ & $\begin{array}{l}\text { Positive } \\
\text { Score }\end{array}$ & $\begin{array}{l}\text { Implemented } \\
\text { before }(\%)\end{array}$ & $\begin{array}{l}\text { Not im- } \\
\text { plementted } \\
\text { before }(\%)\end{array}$ & $\begin{array}{l}\text { Negative } \\
\text { score }\end{array}$ & \\
\hline 1. & Imitation & 59.5 & 24.3 & 83.8 & 2.7 & 13.5 & 16.2 & 12 \\
\hline 2. & $\begin{array}{l}\text { Informal face-to-face interac- } \\
\text { tion }\end{array}$ & 77.0 & 16.2 & 93.2 & 1.4 & 5.4 & 6.8 & 5 \\
\hline 3. & Creation of new roles & 29.7 & 55.4 & 85.1 & 8.1 & 6.8 & 14.9 & 11 \\
\hline 4. & Periodic learning meeting & 78.3 & 20.3 & 98.6 & 0.0 & 1.4 & 1.4 & 1 \\
\hline 5. & Debriefing & 66.1 & 31.0 & 97.1 & 1.4 & 1.45 & 2.9 & 4 \\
\hline 6. & Problem solving techniques & 68.9 & 23.0 & 91.9 & 1.4 & 6.7 & 8.1 & 7 \\
\hline 7. & Learn by helping people & 73.0 & 17.5 & 90.5 & 5.4 & 4.1 & 9.5 & 9 \\
\hline 8. & Simulation & 43.2 & 35.1 & 78.3 & 4.1 & 17.6 & 21.7 & 13 \\
\hline 9. & On job training & 73.0 & 24.2 & 97.2 & 1.4 & 1.4 & 2.8 & 3 \\
\hline 10. & Job variation & 63.5 & 28.3 & 91.8 & 4.1 & 4.1 & 8.2 & 8 \\
\hline 11. & Trial and error & 40.6 & 24.3 & 64.9 & 16.2 & 18.9 & 35.1 & 14 \\
\hline 12. & Extrapolate past events & 68.9 & 20.3 & 89.2 & 5.4 & 5.4 & 10.8 & 10 \\
\hline 13. & Internet Information Searching & 67.5 & 25.6 & 93.1 & 2.7 & 4.1 & 6.9 & 6 \\
\hline 14. & Documentation learning & 81.1 & 16.2 & 97.3 & 1.4 & 1.35 & 2.7 & 2 \\
\hline
\end{tabular}

repeated in the future, avoiding doubling of effort in "reinventing the wheel", thus saving resources and time. The fifth most significant benefit ranked by respondents was "faster resolution of similar problems". Respondents commented that when there was a reference point at the time of a problem, the resolutions got easier. Thus, project learning is an important tool in achieving a faster resolution for a similar problem in the current and future projects.

\subsection{Suitable project learning methods to maximize the utilization of past project histories for better bidding}

As illustrated in Table 5, the five most suitable project learning methods for improvement in bidding were identified through questionnaire survey out of fourteen methods. These five top methods include "periodic learning meeting", "documentation learning", "on job training", "debriefing", and "informal face-to-face interaction".

"Periodic learning meetings" refer to meetings that are held for learning in accordance to a prescribed schedule. It was ranked by respondents as the most suitable project learning method for improving contractors' bid submissions with a positive score at 98.6. Periodic learning meetings form a platform for knowledge of past projects to be generated and captured from the team members. Respondents ranked "documentation learning" as the second most suitable method that can be adopted for the improvement in bidding, with a positive score at 97.3. As refer to Low (2008), this kind of method involves learning from decisions, solutions, and project related information of previous and current projects which have been systematically incorporated into the records of the company. Respondents commented that "documentation learning" was a medium where tacit knowledge could be turned explicit for the quantification of management. "On job trainings" was ranked as the third most suitable project learning methods

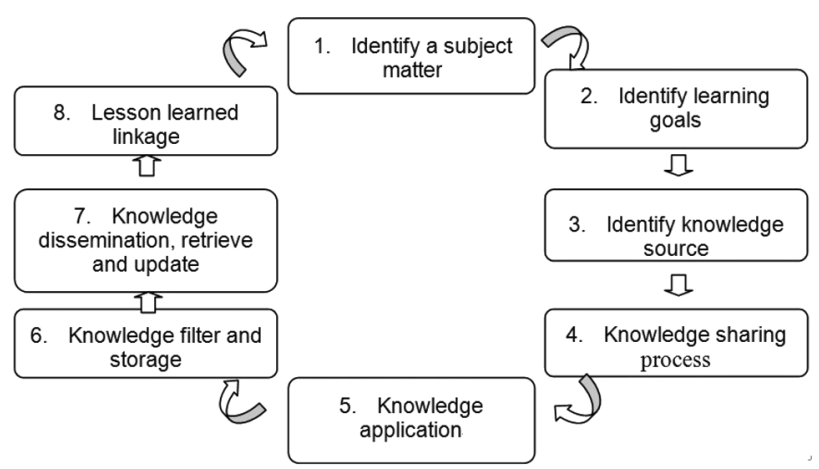

Fig. 2. Continuous project learning model

in improving bid submissions. In fact, all the respondents strongly agreed that "on job training" was an effective method of learning. They commented that "on job training" could provide an organized and well guided way in learning, which ensured the effectiveness and efficiency during the tendering stage. "Debriefing" is a method where individuals being questioned in detail regarding the work that have been executed in terms of lessons learned, failure, success, mistakes and innovation. "Debriefing" was ranked as the fourth most suitable project learning method in improving bidding. As highlighted by Haldin-Herrgard (2000), tacit knowledge is acquired by internal individual process such as internalization, experience, consideration, or individual talents. Therefore, "informal face-to-face interactions" would facilitate the communication of the tacit knowledge among the team members and it was ranked as the fifth most suitable project learning method in improving bidding. Fig. 2 presents the eight phases of the proposed continuous project learning model. The eight phases are:

1) Identify a subject matter: involves the identification of subject matter in respect to project risks, 
problem faced or knowledge gap due to the project constraint;

2) Identify learning goals: composed of identification of learning goals based on the expected value and project requirements;

3) Source of knowledge: project team members explores knowledge base of the subject matter and learning goals to identify the available and unavailable knowledge. In general, knowledge base is divided into tacit and explicit form of knowledge;

4) Knowledge sharing session: contains group discussion in the form of brainstorming, reflection, questioning and multi-way feedback sessions;

5) Knowledge application: makes and evaluates decisions based on the generation of new knowledge;

6) Knowledge filter and storage: filter and store valuable knowledge generated during the knowledge sharing session in a standard template database that contains project name, subject matter, keywords, expert information and knowledge protocol;
7) Knowledge dissemination, retrieve and update: all project parties communicate and retrieve pertinent knowledge or lesson learned through webbased tool. Knowledge protocol is updated at the end of each knowledge sharing process;

8) Lesson learned linkage: form a continuous learning cycle where any lesson learned, principals or new knowledge from past discussion are linked to subsequent discussion to improve the value of the decision making.

\subsection{Development of structured project learning model toward improved bidding}

All lessons learnt throughout the project period should be properly shared, filter, documents and disseminate to prevent the event of knowledge loss which can lead to increase of time in information and knowledge access. A framework for project learning is displayed in Fig. 3 consisting of the techniques used throughout the project time frame, which include integrating learning and knowledge management into project process and adopting project management tools in decision making and problem solving.

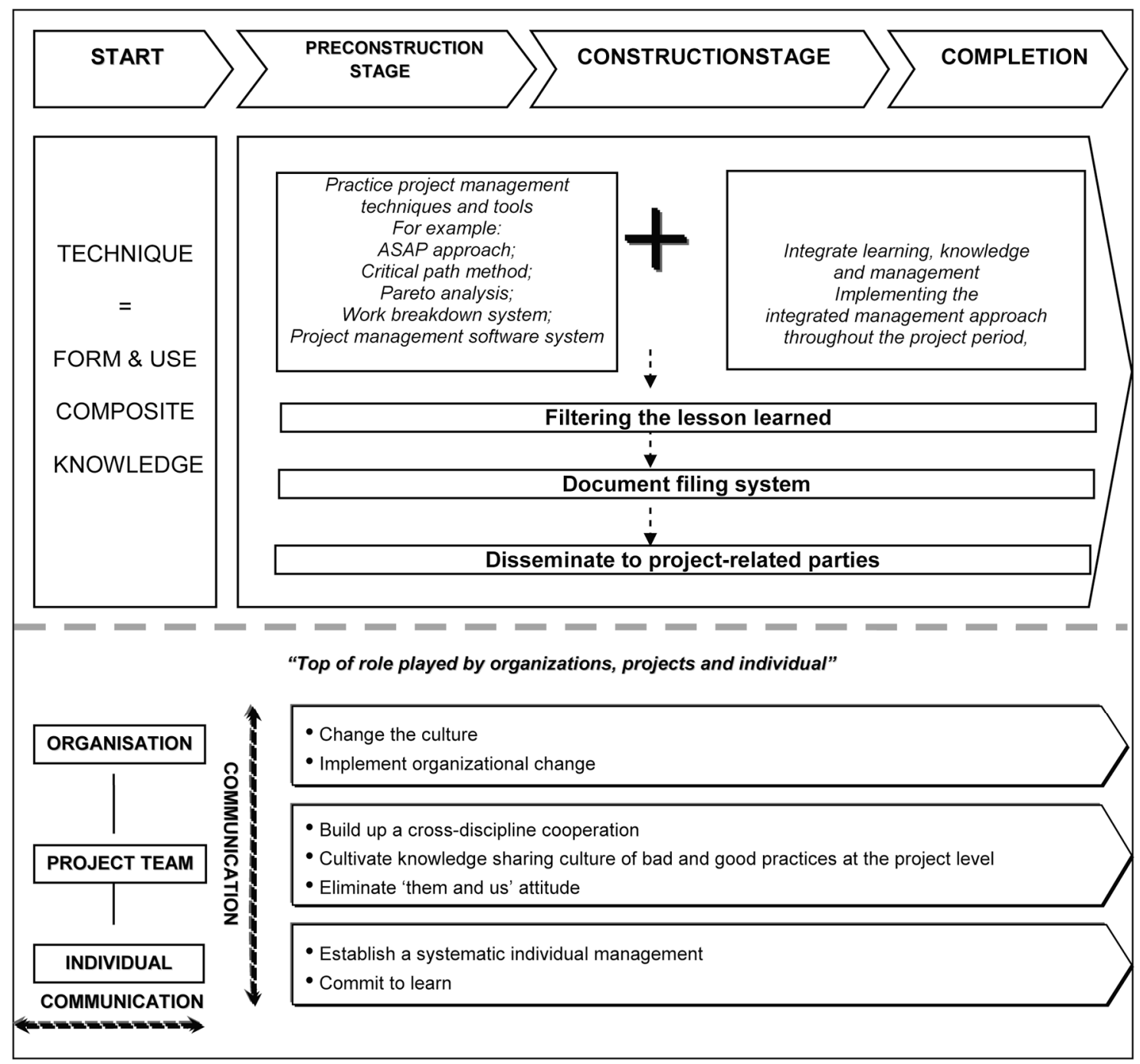

Fig. 3. A developed framework for project learning 


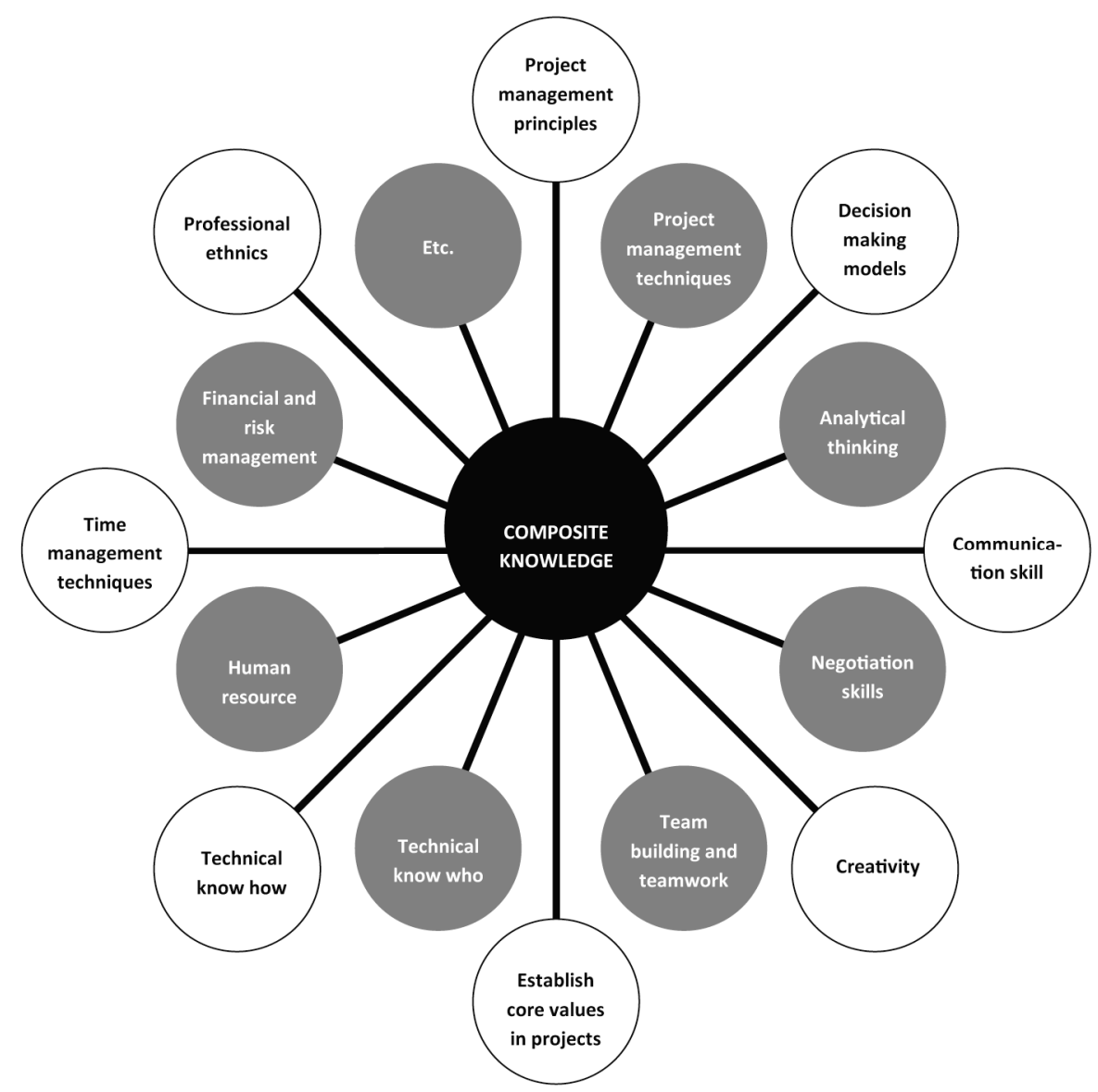

Fig. 4. Composite knowledge

In this framework, the composite knowledge is the different bodies of knowledge being combined to achieve the best outcome at any given time a decision or action is done. Fig. 4 shows the composition of knowledge required in managing construction projects.

At the bottom of the Fig. 3, top of role and action to be played by the organizations, project team, and individual are specified. On the organization aspect, organizations need to perform change in respect of managing knowledge and learning and technology. Cross multidiscipline cooperation is essential to form a project team to cultivate the culture of knowledge sharing and collective learning. The attitude of "them and us" should be ruled out during the project execution. At the individual level, establishment of a systematic individual time management is essential to assure individual focus and time flexibility to carry the task assigned. Individuals should commit to learn and perceive advice and problem as a challenge for future self improvement. Communication plays an important role in preventing wrong decision making and to improve better project coordination.

Drawing on the results and analysis of the four-stage data collection discussed regarding Figs 3 and 4, an structured project learning model toward improved bidding is proposed in Fig. 5. The model is designed specifically for the use in construction projects and with an intention to deal with major bidding factors caused by lack of knowledge and poor management of lessons learned. To assure an effective project learning process throughout the project period, project manager, engineer or experienced personnel should act as a project learning supervisor to ensure each project activities are performed in a knowledge-based manner. The proposed model consists of four main phases. Each phase contains enablers and barriers of project learning that have been accumulated and gathered from the data collection. The four phases in this model are briefly elucidated as follows:

\section{Phase 1: Knowledge identification}

The focal point of knowledge identification is to quantify project activities into several milestones and time goal for each milestone. These activities are based on the characteristics of the project in terms of size and complexity. Each milestone is further explored and classified into five important components as shown in Table 6.

Table 6. Important components of each milestone

\begin{tabular}{l|l}
\hline $\begin{array}{l}\text { Knowledge } \\
\text { content }\end{array}$ & $\begin{array}{l}\text { bodies of knowledge that are essential to com- } \\
\text { plete a particular milestone within specified } \\
\text { time goal }\end{array}$ \\
\hline $\begin{array}{l}\text { Knowledge } \\
\text { gaps }\end{array}$ & $\begin{array}{l}\text { Differences between the knowledge content } \\
\text { and the actual knowledge available }\end{array}$ \\
\hline $\begin{array}{l}\text { Knowledge } \\
\text { risks }\end{array}$ & $\begin{array}{l}\text { Risk associated with accessing of knowledge } \\
\text { content, knowledge gap and alternative } \\
\text { knowledge }\end{array}$ \\
\hline $\begin{array}{l}\text { Alternative } \\
\text { knowledge }\end{array}$ & $\begin{array}{l}\text { knowledge that offers greater possibility to } \\
\text { supersede the core knowledge }\end{array}$ \\
\hline $\begin{array}{l}\text { Knowledge } \\
\text { source }\end{array}$ & $\begin{array}{l}\text { People, previous project documents of the } \\
\text { knowledge content }\end{array}$ \\
\hline
\end{tabular}




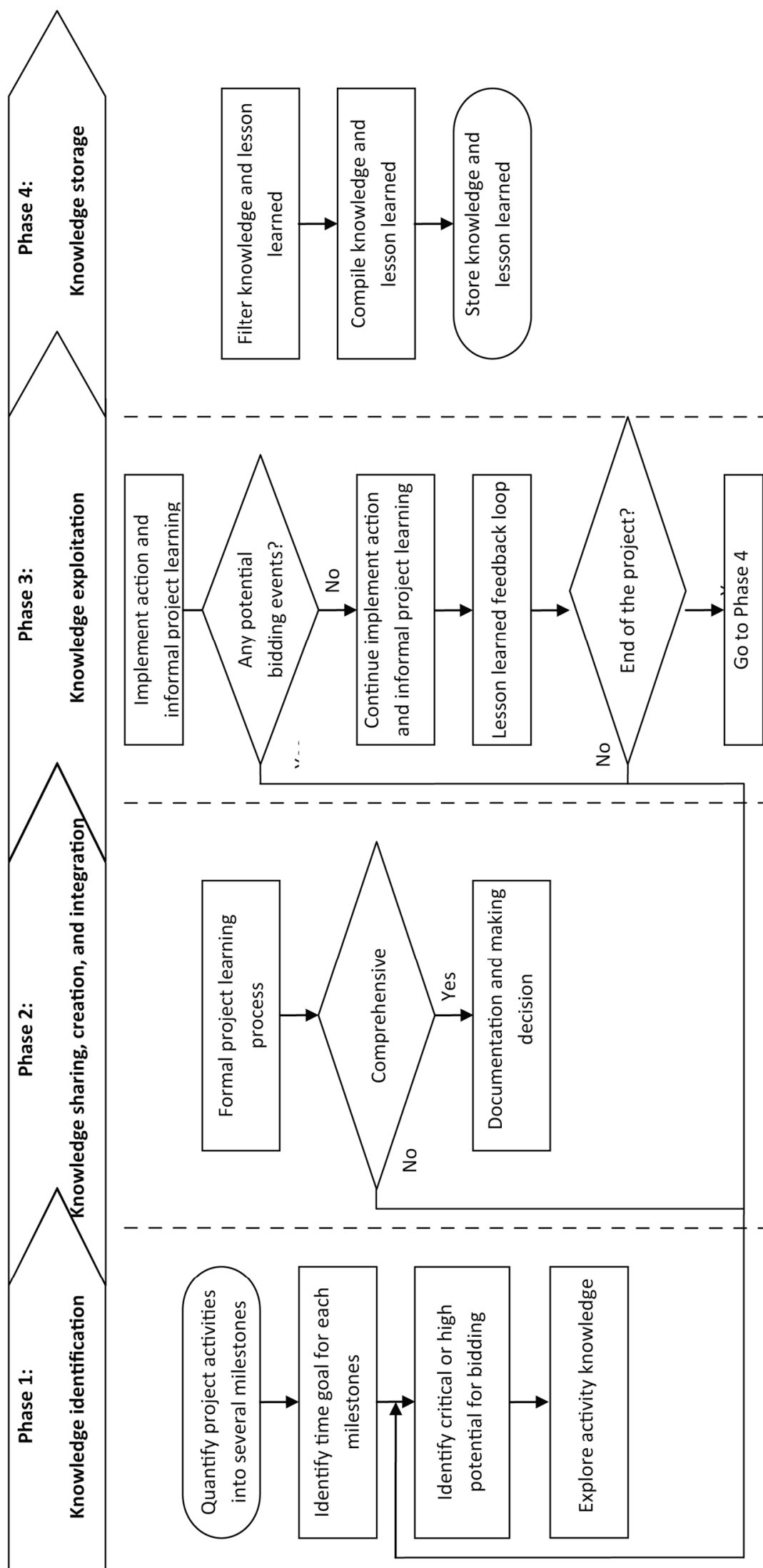

\begin{tabular}{|c|c|c|}
\hline 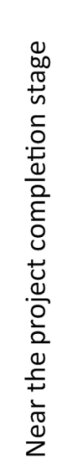 & 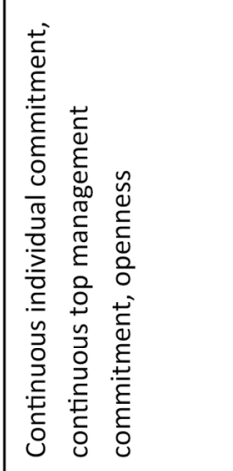 & 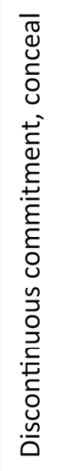 \\
\hline 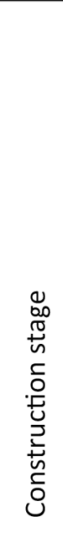 & 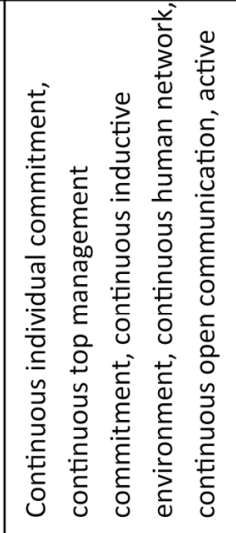 & 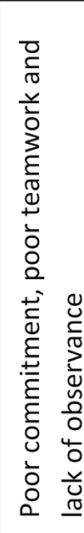 \\
\hline 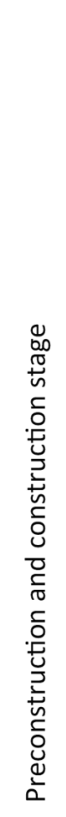 & 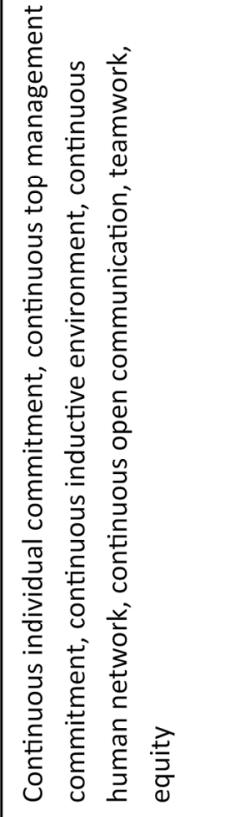 & 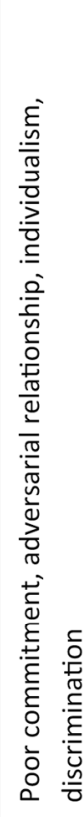 \\
\hline 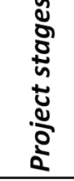 & 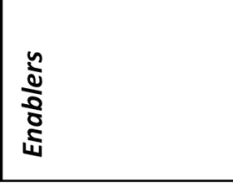 & 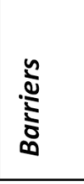 \\
\hline
\end{tabular}

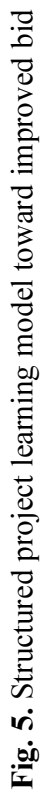




\section{Phase 2: Knowledge sharing, creation and integration}

Formal project learning meeting are held among few key/experienced personnel from each organization. The formal project learning meeting is concerned about the discussion of problems, searching of solution, sharing and exchange of learned mistakes, knowledge and experience. It should be ensured that the outcome of project learning meeting able to integrate the available knowledge to form a new knowledge for the competiveness in bidding. Frequency of organizing project learning meeting depends on the types of problems faced, complexity of the problem and the accessibility of the knowledge content. Generalization using real life case studies is encouraged as project parties can easily establish linkage or connection between current and previous completed project. During the meeting, multi-way feedback should be performed to improve the quality of new knowledge and solution. Relevant and important information and knowledge should be properly documented for the purpose of retrieving and referring. Examination of project learning meeting should be performed to ensure no important elements have been overlooked which can provide negative impact on project schedule performance prior to the finalization of the decision.

\section{Phase 3: Knowledge exploitation}

During performing the project activity, it is important for relevant project parties explore the action taken in respect of the impact of the action taken on subsequent activities and time performance. To exploit knowledge during the construction stage of project, project parties need to track down potential problem, critical events, and potential solutions that can affect a new bidding. Any learned mistakes, learned knowledge and principles of problem solving should be incorporated into feedback report, attach it into project progress report and disseminate to project parties which formed a real time feedback loop. Real time feedback loop ensures other project parties are well informed, similar mistakes do not occur on the subsequent task, and to enable a better informed decision to be made for subsequent project activities.

\section{Phase 4: Knowledge storage}

At the end of the project, knowledge gained throughout the project period is filtered, compiled and stored in a standard template. The standard template should composed of milestone, action taken, types of bid, bidding factors, learned mistake, bad practice, good practice, and critical learned knowledge. These actions aim to avoid loss of valuable knowledge for reference in new bidding and to minimize the problem of information overload in future project.

\section{Discussions on research findings}

"More realistic estimates" was ranked as the second top potential benefit of employing project learning for improved bidding. Actually, this kind of benefit was also suggested by Maqsood et al. (2006) that having project learning put into practice, the construction company would be able to produce more realistic estimates and the experiences from past projects would educate the estimators with the "do's and don'ts" in estimating. "less rework and repetition of mistakes" was the fourth potential benefit of employing project learning for improved bidding and was considered essential to ensure that errors and mistakes are not repeated in the future, avoiding doubling of effort in "reinventing the wheel", thus saving resources and time. Actually, this kind of benefit was also highlighted by Williams (2008), Manjula and Mustapha (2006), Disterer (2002), Maqsood et al. (2006). "Improved accuracy in pricing" and "better evaluation of risks involved in tendering for a project" were ranked in the top five potential benefits of employing project learning for improved bidding for the first time in this survey. This is probably because the current status in the accuracy in bidding pricing in the Malaysian construction industry is not satisfactory compared to the context in Williams (2008), Manjula and Mustapha (2006), Disterer (2002), Maqsood et al. (2006).

Dodgson et al. (2007) highlighted the impact of modeling and simulation technology on engineering problem solving and Brady et al. (2006) discussed the role of learning to manage mega projects. Further, Plaza and Turetken (2009) proposed a model-based DSS for integrating the impact of learning in project control. Sense (2003) developed a model for the politics of project leader learning. However, neither Plaza and Tureken's (2009) nor Sense's (2003) learning model focused on the competitiveness in bidding. The proposed model in this study tends to be more capable to enhance learning, knowledge sharing, and individual knowledge seeking for construction project bidding. Drawing on existing arguments, increased profit (Macher 1992) and increased knowledge, which may be either tacit or explicit (Rowley 2000) are after-the-fact indicators that learning is occurring. Accordingly, Winch (2002) affirmed that effective learning within the project deploys the new value creation to the project. Thus, it can be expected that the application of the proposed model is capable to enhance the sustainability in project bidding. Nevertheless, it is the significant value of the project is difficult to foresee in reality due to environment, human and other unforeseen factors.

The strength of the proposed model is that it focuses on project knowledge and continuous collective learning in which both elements are critical in enhancing the value of the construction projects. While, the potential shortcomings of this model are that it is built on an unproved premise and the model seem to be suitable for moderate large and complex project bidding. The samples selected in the data collection were only class " $\mathrm{A}$ " contractors who have registered themselves with the "Pusat Khidmat Kontraktor" (PKK 2010). Contractors who belong to class "A" represented the highest financial limits and worked towards the ISO 9001 accreditation. However, this has brought the limitation in universality to this study. Future study should cover small and medium sized contractors. Further, questionnaires were distributed to only private based construction companies in Malaysia. 
As the public sector was not covered in this study, it could be considered in future research.

\section{Conclusions and recommendations for future research}

It is a good indication that contractors began to recognize the significance of project learning as an approach to improve the quality of their bids. However, a potential draw back in the employment of project learning is that it is not carried out in a structured and systematic manner. Very few construction companies have assigned individuals specifically for the purpose of project learning. Through a questionnaire survey, the five most significant benefits from project learning for the betterment of bid submissions were identified, namely: "improved accuracy in pricing", "more realistic estimates", "better evaluation of risks involved in tendering for a project", "less rework and repetition of mistakes", and "faster resolution of similar problems". Further, the five most suitable project learning methods for improvement in bidding were recommended, which included "periodic learning meeting", "documentation learning", "on job training", "debriefing", and "informal face-to-face interaction". Accordingly, a structured project learning model toward improved bidding is developed for large construction firms. Comparing to Plaza and Tureken's (2009) or Sense's (2003) learning model, the proposed model in this study tends to be more capable to enhance learning, knowledge sharing, and individual knowledge seeking for construction project bidding. Future study should cover small and medium sized contractors as well as contractors in the public sector to enhance the universality and sustainability of this learning model. Further, the developed model needs to be improved more detailed to cover the commissioning stage which was not covered in this study.

\section{References}

Amarjit, S.; Shoura, M. M. 1998. Optimization for bidder profitability and contractor selection, Cost Engineering 40(6): 31-41.

Brady, T.; Davies, A.; Gann, D.; Rush, H. 2006. Learning to manage mega projects: The case of BAA and Heathrow Terminal 5, in IRNOP VII Project Research Conference, 11-13 October, 2006, Xi'an, China.

Cambridge Advanced Learner's Dictionary. Cambridge University Press, 1992. 1562 p.

Davenport, T. H.; De-Long, D. W.; Beers, M. C. 1998. Successful knowledge management projects, Sloan Management Review 1: 43-55.

Disterer, G. 2002. Management of project knowledge and experiences, Journal of Knowledge Management 6(5): 512-520. http://dx.doi.org/10.1108/13673270210450450

Djaiz, C.; Matta, N. 2006. Aggregation method to reuse knowledge from project memory, in Knowledge Management International Conference and Exhibition (KMICE), 6-8 June, 2006, Kuala Lumpur, Malaysia, 9098.

Dodgson, M.; Gann, D. M.; Salter, A. 2007. The impact of modelling and simulation technology on engineering problem solving, Technology Analysis \& Strategic Management 19(4): 471-489.

http://dx.doi.org/10.1080/09537320701403425
Greiner, M. E.; Böhmann, T.; Krcmar, H. 2007. A strategy for knowledge management, Journal of Knowledge Management 11(6): 3-15.

http://dx.doi.org/10.1108/13673270710832127

Haldin-Herrgard, T. 2000. Difficulties in diffusion of tacit knowledge in organizations, Journal of Intellectual Capital 1(4): 357-365.

http://dx.doi.org/10.1108/14691930010359252

Heo, H.; Lim, K. Y.; Kim, Y. 2010. Exploratory study on the patterns of online interaction and knowledge coconstruction in project-based learning, Computers \& Education 55(3): 1383-1392.

http://dx.doi.org/10.1016/j.compedu.2010.06.012

Jashapara, A. 2004. Knowledge management: An integrated approach. Harlow, England: Pearson Education Limited. $344 \mathrm{p}$.

Kanapeckiene, L.; Kaklauskas, A.; Zavadskas, E. K.; Seniut, M. 2010. Integrated knowledge management model and system for construction projects, Engineering Applications of Artificial Intelligence 23(7): 1200-1215.

http://dx.doi.org/10.1016/j.engappai.2010.01.030

Kim, S.-G. 2010. Risk performance indexes and measurement systems for mega construction projects, Journal of Civil Engineering and Management 16(4): 586-594. http://dx.doi.org/10.3846/jcem.2010.65

Low, W.W. 2008. The use of project learning to enhance the value of construction projects. Msc Thesis. University of Malaya. $278 \mathrm{p}$.

Macher, K. 1992. Organizations that learn, Journal for Quality \& Participation 15(7): 8-11.

Macmillan English Dictionary. Macmillan Education Ltd, 2002. $1872 \mathrm{p}$.

Manjula, J.; Mustapha, S. M. 2006. Issues on knowledge management in organisations today, in Knowledge Management International Conference and Exhibition (KMICE), 6-8 June, 2006, Kuala Lumpur, Malaysia, 225231.

Maqsood, T.; Finegan, A.; Walker, D. 2006. Applying project histories and project learning through knowledge management in an Australian construction company, Learning Organization 13(1): 80-95. http://dx.doi.org/10.1108/09696470610639149

McIntyre, M. 2007. Risky Business, Construction Business Owner 1: 62-65.

Mohamed, S. F.; Anumba, C. J. 2006. Potential for improving site management practices through knowledge management, Construction Innovation 6: 232-249. http://dx.doi.org/10.1108/14714170610713917

Park, M.; Lee, H.-S.; Kwon, S. 2010. Construction knowledge evaluation using expert index, Journal of Civil Engineering and Management 16(3): 401-411. http://dx.doi.org/10.3846/jcem.2010.46

Pathirage, C. P.; Amaratunga, D. G.; Haigh, R. P. 2007. Tacit knowledge and organisational performance: construction industry perspective, Journal of Knowledge Management 11(1): 115-126. http://dx.doi.org/10.1108/13673270710728277

Plaza, M.; Turetken, O. 2009. A model-based DSS for integrating the impact of learning in project control, Decision Support Systems 47(4): 488-499. http://dx.doi.org/10.1016/j.dss.2009.04.010

Pusat Khidmat Kontraktor (PKK). 2010. [cited 16 October, 2010], Available from Internet: $<$ http://pkk.mecd.gov.my/index.php?option=com_content andtask $=$ viewandid=26andItemid $=40>$. 
Rezgui, Y.; Hopfe, C. J.; Vorakulpipat, C. 2010. Generations of knowledge management in the architecture, engineering and construction industry: An evolutionary perspective, Advanced Engineering Informatics 24(2): 219-228. http://dx.doi.org/10.1016/j.aei.2009.12.001

Rowley, J. 2000. From learning organization to knowledge entrepreneur, Journal of Knowledge Management 4(1): 715. http://dx.doi.org/10.1108/13673270010315362

Schindler, M.; Eppler, M. J. 2003. Harvesting project knowledge: A review of project learning methods and success factors, International Journal of Project Management 21(3): 219-228. http://dx.doi.org/10.1016/S0263-7863(02)00096-0

Sense, A. J. 2003. A model of the politics of project leader learning, International Journal of Project Management 21(2): 107-114.

http://dx.doi.org/10.1016/S0263-7863(02)00018-2
Tserng, H. P.; Yin, S. Y.-L.; Lee, M.-H. 2010. The use of knowledge map model in construction industry, Journal of Civil Engineering and Management 16(3): 332-344. http://dx.doi.org/10.3846/jcem.2010.38

Williams, T. 2008. How do organizations learn lessons from projects - and do they? IEEE Transactions on Engineering Management 55(2): 248-266. http://dx.doi.org/10.1109/TEM.2007.912920

Winch, G. M. 2002. Managing construction projects. Oxford: Blackwell Publishing Limited. $544 \mathrm{p}$.

Wong, P. S. P.; Cheung, S. O.; Wu, R. T. H. 2010. Learning from project monitoring feedback: A case of optimizing behavior of contractors, International Journal of Project Management 28(5): 469-481.

http://dx.doi.org/10.1016/j.ijproman.2009.07.003

Hamzah ABDUL-RAHMAN. Professor of Construction Management in the Faculty of Built Environment, University of Malaya, Malaysia. He is currently serving as the Deputy Vice Chancellor (Research \& Innovation) of University of Malaya. He was previously serving as the Deputy Vice Chancellor (Academic \& International) of University of Malaya. His research interests include the construction innovation, project management, building energy efficiency, and industrialized building system (IBS). He is also a fellow member of the Chartered Institute of Surveyors, United Kingdom (International).

Chen WANG. Dr, Senior Research Fellow of Construction Innovation and Project Management in the Faculty of Built Environment, University of Malaya. He was a senior engineer of China State Construction Engineering Corporation (CSCEC). His research interests include the sustainability in construction management, international BOT projects, mathematics modeling, and building integrated solar application. He is also a member of The Chinese Research Institute of Construction Management (CRIOCM), Hong Kong (International).

Shamini Batu MALAY. Research fellow of Facility Management in the Faculty of Built Environment, University of Malaya. His research interests include facility management, engineering modeling, and total quality management. 